\title{
PCA3 Silencing Sensitizes Prostate Cancer Cells to Enzalutamide-mediated Androgen Receptor Blockade
}

\author{
EMRE ÖZGÜR, AYCA IRIBAS CELIK, EMIN DARENDELILER and UGUR GEZER \\ Oncology Institute, Istanbul University, Istanbul, Turkey
}

\begin{abstract}
Background/Aim: Prostate cancer (PCa) is an androgen-dependent disease. Novel anti-androgens (i.e. enzalutamide) have recently been developed for the treatment of patients with metastatic castration-resistant prostate cancer (CRPC). Evidence is accumulating that prostate cancer antigen 3 (PCA3) is involved in androgen receptor $(A R)$ signaling. Here, in combination with enzalutamidemediated AR blockade, we investigated the effect of PCA3 targeting on the viability of $P C a$ cells. Materials and Methods: In hormone-sensitive LNCaP cells, ARoverexpressing LNCaP-AR ${ }^{+}$cells and VCaP cells (representing CRPC), PCA3 was silenced using siRNA oligonucleotides. Gene expression and cell viability was assessed in PCA3-silenced and/or AR-blocked cells. Results: PCA3 targeting reduced the expression of AR-related genes (i.e. prostate-specific antigen (PSA) and prostate-specific transcript 1 (non-protein coding) (PCGEMI)) and potentiated the effect of enzalutamide. Proliferation of $\mathrm{PCa}$ cells was suppressed upon PCA3 silencing with a greater effect in LNCaP-AR ${ }^{+}$cells. Furthermore, PCA3 silencing sensitized PCa cells to enzalutamide-induced loss of cell growth. Conclusion: PCA3, as a therapeutic target in $P C a$, might be used to potentiate AR antagonists.
\end{abstract}

Prostate cancer ( $\mathrm{PCa})$ is the most commonly diagnosed cancer in men in Western countries. Despite recent reductions in mortality, it continues to be a major cause of cancer-related death (1). PCa is an androgen receptor (AR) pathway-driven and androgen-dependent disease and the suppression of AR by surgical or medical castration results in tumor regression (2). Despite a high response rate with

Correspondence to: Dr. Ugur Gezer, Department of Basic Oncology, Omcology Institute, Istanbul University, Capa 34093, Istanbul, Turkey. Tel: +90 2124142434, Fax: +90 2125348078, e-mail: ugurd@istanbul.edu.tr

Key Words: Prostate cancer, PCA3, enzalutamide, androgen receptor. androgen deprivation, most patients with metastatic disease progress to castration-resistant prostate cancer (CRPC) as a consequence of continuous AR activation (3). Progression to CRPC cuts the expected survival time down to around 1618 months (4).

Novel anti-androgens have been developed in recent years because androgens and AR signaling represent the main targets of PCa treatment strategies. Of these, enzalutamide (formerly MDV3100) is a non-steroidal second-generation anti-androgen that has been approved for treatment of patients with metastatic CRPC. Enzalutamide inhibits multiple steps of AR signaling: binding of androgens to AR, nuclear translocation of AR and association of AR with DNA (5). It blocks the growth of CRPC in cell model systems (6).

Prostate cancer antigen 3 (PCA3), initially known as differential display code 3 (DD3), is an emerging molecule in PCa. PCA3 gene is located on chromosome 9q21-22 and embedded in antisense orientation within the intronic region of the PRUNE2 gene (7). It encodes a prostate-specific long non-coding RNA (8). PCA3 has been shown to be expressed in much higher levels in cancerous prostate tissues compared with benign prostate tissues (9). Urinary PCA3 has recently been studied extensively for the prediction of prostate biopsy results and treatment outcomes (10).

Recent data revealed that $P C A 3$ is involved in AR signaling because it was induced by androgens $(11,12)$ and regulates key cancer-related genes in PCa cells (13). Targeting PCA3 expression results in loss of cell growth, supporting the proposal that PCA3 may serve as a target of therapeutic approach to inhibit PCa growth $(11,13)$. Here, we designed an in vitro investigation to study the effect of PCA3 targeting on AR-related genes and the viability of PCa cells, in combination with enzalutamide-mediated AR inhibition.

\section{Materials and Methods}

Cell lines and cell culture. We used 3 cell lines: LNCaP, LNCaP$\mathrm{AR}^{+}$and $\mathrm{VCaP}$ cells. The $\mathrm{LNCaP}$ cell line is androgen-sensitive and derived from human prostate adenocarcinoma cells from a lymph node metastasis. The $\mathrm{LNCaP}-\mathrm{AR}^{+}$cell line is a modified version of 
LNCaP overexpressing AR. $\mathrm{VCaP}$ cells are a $\mathrm{PCa}$ cell line established from a vertebral metastatic lesion (14). This cell line expresses a wild-type androgen receptor but can grow in an androgen-independent manner, making it an ideal cell line for studying CRPC $(14,15)$. $\mathrm{LNCaP}$ and $\mathrm{VCaP}$ cell lines were purchased from ATCC (Rockville, MD, USA), while the LNCaP$\mathrm{AR}^{+}$cell line was a kind gift of the Charles Sawyers Lab (Memorial Sloan Kettering Cancer Center, New York, NY, USA). LNCaP and LNCaP-AR ${ }^{+}$were cultured in an RPMI-1640 medium containing $\mathrm{NaHCO}_{3}(3.7 \mathrm{~g} / \mathrm{l})$, glucose $(1 \mathrm{~g} / \mathrm{l})$ and stabile glutamine (Biochrom, Berlin, Germany) supplemented with $10 \%$ fetal calf serum (FCS) (Biochrom) and antibiotics under standard conditions $\left(37^{\circ} \mathrm{C}\right.$ and $5 \%$ $\mathrm{CO}_{2}$ humidity). VCaP cells were maintained in DMEM (Biochrom) supplemented with $10 \%$ FCS and antibiotics. We confirmed that all 3 cell lines expressed $P C A 3$.

Small interfering RNA (siRNA)-mediated PCA3 knockdown. We used siRNAs, which were previously reported to efficiently target the PCA3 gene (11). The sequences of the oligonucleotide-targeting $P C A 3$ exon 4 (siPCA3) and negative scramble (SCR) control siRNA (siSCR) were as follows: siPCA3: 5'-CUAGCACACAGCAUG AUCAUUACGG-3' and SiSCR: 5'-GCACGCUCCUACGAAUGC UAGUAAA-3' (IDT Technologies, Coralville, IA, USA). One day before siRNA transfection, cells were seeded at a density of $2 \times 10^{5}$ cells in $35 \times 10-\mathrm{mm}$ culture dishes. After $24 \mathrm{~h}$, the medium in the dishes was replaced with $1.5 \mathrm{ml}$ of fresh medium and transfected with $60 \mathrm{nM}$ of each siRNA-targeting $P C A 3$ or a control siRNA, using Lipofectamine 2000 (Invitrogen, Waltham, MA, USA) according to the manufacturer's protocol. Six hours later, the medium was replaced by fresh growth medium. Cells were then kept in culture up to 36 or $72 \mathrm{~h}$ before harvesting for further analysis.

Androgen receptor blockade. In order to inhibit AR, we used a secondgeneration AR antagonist, enzalutamide (kindly donated by Astellas Inc., Northbrook, IL, USA). To accomplish this, cells were seeded at a density of $2 \times 10^{5}$ cells in $35 \times 10$-mm petri dishes and grown in hormone-free conditions (e.g. charcoal-treated serum) for 3 days. The medium was replaced with fresh medium containing enzalutamide or control (dimethyl sulfoxide (DMSO)) and the cells were then allowed to grow for up to $72 \mathrm{~h}$. Based on pre-experiments, we applied two submaximal doses (500 and/or 5,000 nM) of enzalutamide for different purposes. When PCA3 silencing and enzalutamide was combined following 3 days of growth in hormone-free milieu, cells were transfected with siPCA3 or siSCR and enzalutamide was added $6 \mathrm{~h}$ after transfection at medium replacement.

Irradiation of cells. To investigate whether $P C A 3$ silencing had an additive effect on survival of irradiated cells, cells were irradiated to total doses of 0 and 5 Gy using a Cobalt-60 c-ray source at a dose rate of $200 \mathrm{cGy} / \mathrm{min}$ and kept under standard growth conditions for up to $72 \mathrm{~h}$. If combined with $P C A 3$ knockdown, cells were irradiated $6 \mathrm{~h}$ after transfection at medium replacement.

Analysis of gene expression. Expression of $P C A 3$ and AR-related genes (prostate-specific antigen $(P S A)$, prostate-specific transcript 1 (non-protein coding) (PCGEM1), prostate cancer associated noncoding RNA 1 (PRNCRI)) was investigated using quantitative realtime polymerase chain reaction (PCR). First, total RNA from cultured cells was extracted using the TriPure Isolation Reagent (Roche, Mannheim, Germany), according to the manufacturers' instructions. Total RNA was used for complementary DNA (cDNA) synthesis using a First-Strand cDNA Synthesis kit (Thermo Scientific, Waltham, MA, USA), in accordance with the manufacturers' instructions. Expression analysis was performed using a LightCycler 480 instrument (Roche) and SYBR Green (Roche) as the fluorescent molecule. Results were standardized to the housekeeping gene glyceraldehyde 3-phosphate dehydrogenase (GAPDH). The PCR program included an initial hot start of $10 \mathrm{~min}$, followed by 45 cycles of amplification. Each cycle consisted of a denaturation step at $95^{\circ} \mathrm{C}$ for $10 \mathrm{~s}$, annealing starting at $60^{\circ} \mathrm{C}$ for $20 \mathrm{~s}$ and decreasing $2^{\circ} \mathrm{C}$ every 2 cycles until $55^{\circ} \mathrm{C}$, as well as amplification at $72^{\circ} \mathrm{C}$ for $30 \mathrm{~s}$.

Assessment of cell viability. The viability of PCa cells following PCA3 silencing and/or AR blockade was evaluated using two different approaches: first, we monitored the growth of PCa cells using real-time cellular analysis with the microelectronic biosensorbased iCELLigence instrument (ACEA Biosciences, San Diego CA, USA). Secondly, we employed a clonogenic assay to evaluate cytotoxicity.

In real-time cellular analysis systems, numeric cell changes affect the local ionic environment at the electrode/solution interface, leading to an increase or decrease in electrode impedance. Data are recorded as impedance change and expressed as a cell index (CI) as a mean of cell proliferation. After determining CI, results were expressed as a percentage of the control cells. For that analysis, 25,000 cells were used. Monitoring of the cells in the instrument began $24 \mathrm{~h}$ before transfection. The medium was replaced following transfection and drug was added $(6 \mathrm{~h})$; cells were then monitored for up to $72 \mathrm{~h}$ (total monitoring period $102 \mathrm{~h}$ ).

In the colony formation assay, $36 \mathrm{~h}$ after transfection and/or drug treatment, cells were harvested and single cell suspensions were prepared. Five thousand cells were re-plated on $35 \times 10-\mathrm{mm}$ Petri dishes and were grown for a further 10-day period. After removing the culture medium and washing, colonies were fixed with glutaraldehyde $(6.0 \% \mathrm{v} / \mathrm{v})$ and stained with crystal violet dye $(0.01 \%(\mathrm{w} / \mathrm{v}))$ for $30 \mathrm{~min}$. The number of colonies were then counted. Plating efficiency and surviving fraction were calculated according to the following formulas:

Plating efficiency=number of colonies counted/ number of cells plated and

Surviving fraction=(number of colonies counted/ number of cells plated)/plating efficiency

Measurement of apoptotic cell death. The effect of PCA3 silencing in combination with AR inhibition or irradiation on cell death rates was assessed using the Cell Death Detection enzyme-linked immunosorbent assay (ELISA) Kit (Roche). In this assay, cytoplasmic levels of mono- and oligonucleosomes that were released into the cytoplasm during apoptosis prior to membrane breakdown are measured. For this assay, we used $15 \times 10^{4}$ cells and the analysis was performed as previously described (16). In brief, after removing swimming cells from the culture suspension, adherent cells were harvested and cytoplasmic lysates were applied for the measurement.

Statistical analysis. We assessed the results of at least 2 independent cell culture experiments. Changes in gene expression or apoptotic cell death rates relative to basal levels were expressed as 'fold changes' and mean values were statistically compared using the independent-test. Changes in rates of cell viability were expressed 
as a percentage of the control cells. All $p$-values $<0.05$ were considered to be significant.

\section{Results}

siRNA-mediated targeting leads to effective PCA3 knockdown. $\mathrm{LNCaP}, \mathrm{LNCaP}-\mathrm{AR}^{+}$and $\mathrm{VCaP}$ cells were transfected with control siRNA (siSCR) or PCA3-targeting siRNA (siPCA3) and $P C A 3$ expression was evaluated $36 \mathrm{~h}$ after transfection using qPCR. As illustrated in Figure 1, $P C A 3$ was efficiently suppressed in all 3 cell lines with average rates of $82 \%, 78 \%$ and $79 \%$ in $\mathrm{LNCaP}, \mathrm{LNCaP}-\mathrm{AR}^{+}$ and $\mathrm{VCaP}$ cells, respectively. The extent of silencing was statistically significant for all cell lines $(p<0.05)$.

Enzalutamide-mediated AR blockade mimics siRNA-mediated $P C A 3$ targeting. We were interested whether AR inhibition would have an effect on $P C A 3$ expression. For this, we treated the cells with $500 \mathrm{nM}$ of enzalutamide for $36 \mathrm{~h}$ and examined PCA3 expression (Figure 1). Mimicking siRNAmediated $P C A 3$ targeting, we identified a decline (43\% in average) in PCA3 expression following AR inhibition in $\mathrm{LNCaP}$ and $\mathrm{LNCaP}-\mathrm{AR}^{+}$. Unexpectedly, enzalutamide had no effect on $P C A 3$ in $\mathrm{VCaP}$ cells. The combination of $P C A 3$ silencing and enzalutamide synergistically suppressed $P C A 3$, further, with the most apparent effect in AR-overexpressing $\mathrm{LNCaP}_{-} \mathrm{AR}^{+}$cells $(p<0.05)$ (Figure 1$)$.

PCA3 knockdown boosts enzalutamide-mediated downregulation of $A R$-related genes. In combination with $\mathrm{AR}$ inhibition, we next assessed the effect of $P C A 3$ silencing on the androgen target gene PSA and two androgen signalingrelated non-coding RNAs, i.e. PCGEMI and PRNCRI (17). The effect of enzalutamide treatment $(500 \mathrm{nM})$ on those genes was $P S A>P C G E M 1>P R N C 1$. Interestingly, enzalutamide weakly affected PRNC1 (approx. 10\% decline in expression). $P C A 3$ silencing mimicked enzalutamide-mediated blocking of AR signaling and efficiently cut the expression of PSA in $\mathrm{LNCaP}_{-} \mathrm{AR}^{+}$cells (approx. 50\%). For $\mathrm{LNCaP}$ and $\mathrm{VCaP}$ cells, the effect was lower (30-35\%). PCGEMI was down-regulated around $40 \%$ in $\mathrm{LNCaP}-\mathrm{AR}^{+}$and $\mathrm{VCaP}$ cells, whereas the effect was slightly lower in LNCaP cells. Similar to enzalutamide treatment, $P C A 3$ targeting had a small effect on PRNCA1 (approx. 10\%). The combination of AR inhibition with PCA3 silencing led to a further decline of target genes $(P S A>P C G E M 1>P R N C 1)$. Figure 2 demonstrates the effect of AR inhibition, PCA3 silencing and their combination on AR-related genes in $\mathrm{LNCaP}_{-} \mathrm{AR}^{+}$cells.

PCA3 knockdown sensitizes PCa cells to enzalutamide. We next explored the effect of $P C A 3$ targeting on the survival of $\mathrm{PCa}$ cells, in combination with enzalutamide. Proliferation of PCa cells was monitored using real-time cell analysis (Figure
3) and the results (as percentage of control cells) at 36- and 72-h time points are given in Table I. As expected, enzalutamide reduced the growth of PCa cells in a dose- and time-dependent manner up to $32 \%$ at $72 \mathrm{~h}$. The effect was lower in VCaP cells (21\%). PCA3 silencing was also effective and led to a loss of cell growth up to $20 \%$ (compared with

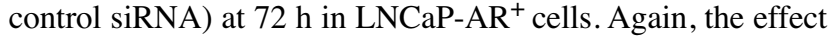
was limited $(6 \%)$ in $\mathrm{VCaP}$ cells. In the combined setting, $P C A 3$ silencing increased the anti-proliferative effect of enzalutamide, especially that of the high dose. LNCaP-AR ${ }^{+}$ cells were more sensitive to AR blockade/PCA3 silencing than LNCaP and VCaP cells, which indicated that higher AR expression underlies increased sensitivity.

The cytotoxic effect of the treatments was better seen in the clonogenic assay. Table II illustrates surviving fractions (as percentage changes of control cells) of PCa cells exposed to AR inhibition, PCA3 silencing or their combination following 10 days of incubation. $P C A 3$ targeting was as effective as enzalutamide and decreased cell viability up to $28 \%$ as compared with the siRNA control in $\mathrm{LNCaP}-\mathrm{AR}^{+}$cells. The effect was lowest $(11 \%)$ in VCaP cells. Expectedly, PCA3 silencing increased the enzalutamide effect a further $31 \%$ in the $\mathrm{LNCaP}-\mathrm{AR}^{+}$cells. The data from the clonogenic assay confirm that $P C A 3$ silencing suppresses the proliferation of PCa cells and sensitizes them to AR blockade and that higher AR expression underlies the mechanism of $P C A 3$ activity.

PCA3 targeting increases the cell killing effect of enzalutamide and ionizing radiation. At $36 \mathrm{~h}$ of incubation, we evaluated cell death rates in PCa cells transfected with siPCA3 and exposed to enzalutamide (500 nM) and/or irradiation ( $5 \mathrm{~Gy}$ ). Apoptotic cell death was investigated by measuring oligonucleosomes that were released into the cytoplasm from early phases of apoptosis induction. The results are summarized in Table III. Even if low-dose enzalutamide $(500 \mathrm{nM})$ had a very small anti-growth effect (see Table I), we detected a significant level of cytoplasmic oligonucleosomes in all cell lines (2.1- to 2.8-fold) revealing the onset of apoptosis in still intact cells. The effect of irradiation was lower (1.6- to 1.9-fold) than enzalutamide. $P C A 3$ targeting itself induced apoptotic cell death in all 3 cell types and potentiated the cell killing activity of enzalutamide, radiation and their combination.

\section{Discussion}

In this work, we aimed to study the effect of $P C A 3$ targeting on AR-related genes and the viability of PCa cells. Using cell lines representing hormone-sensitive PCa (LNCaP), ARoverexpressing $\mathrm{PCa}\left(\mathrm{LNCaP}-\mathrm{AR}^{+}\right)$and $\mathrm{CRPC}(\mathrm{VCaP})$, we investigated the potential of $P C A 3$ as a therapeutic target in $\mathrm{PCa}$ in combination with enzalutamide-mediated AR inhibition and/or ionizing radiation. 

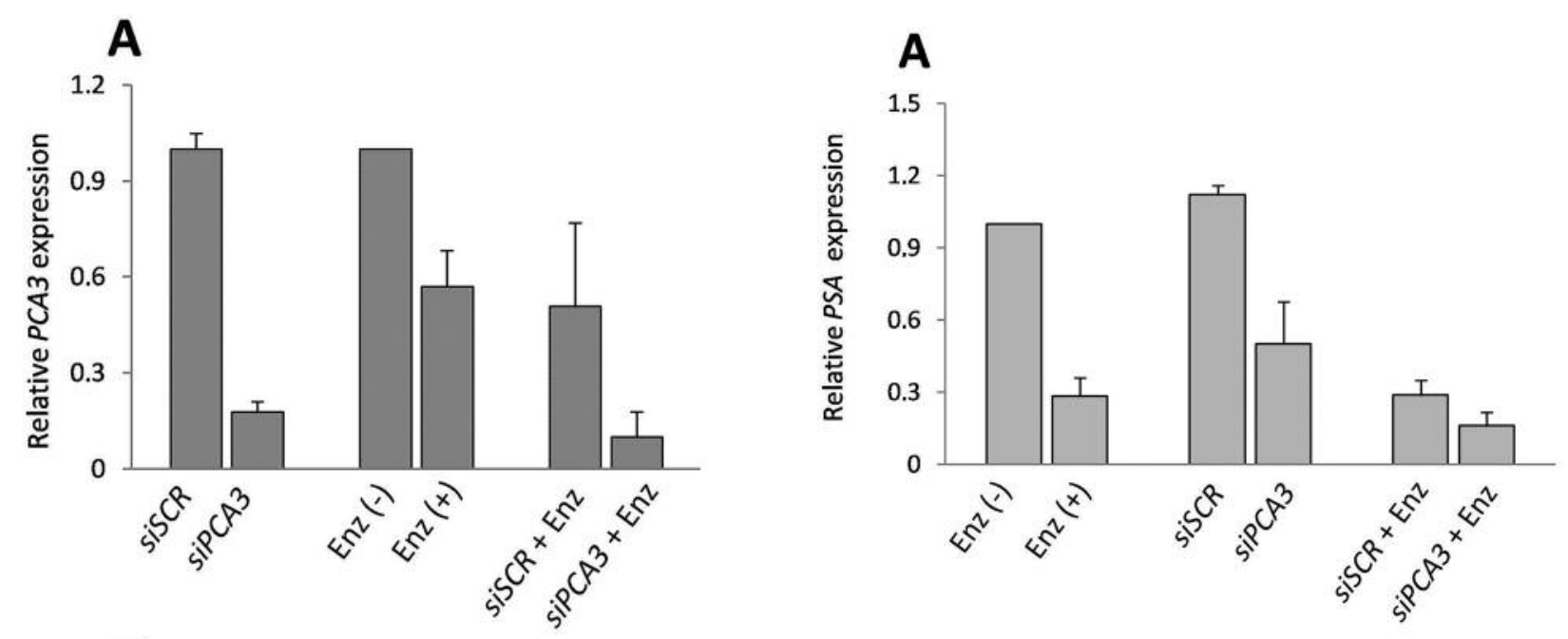

B
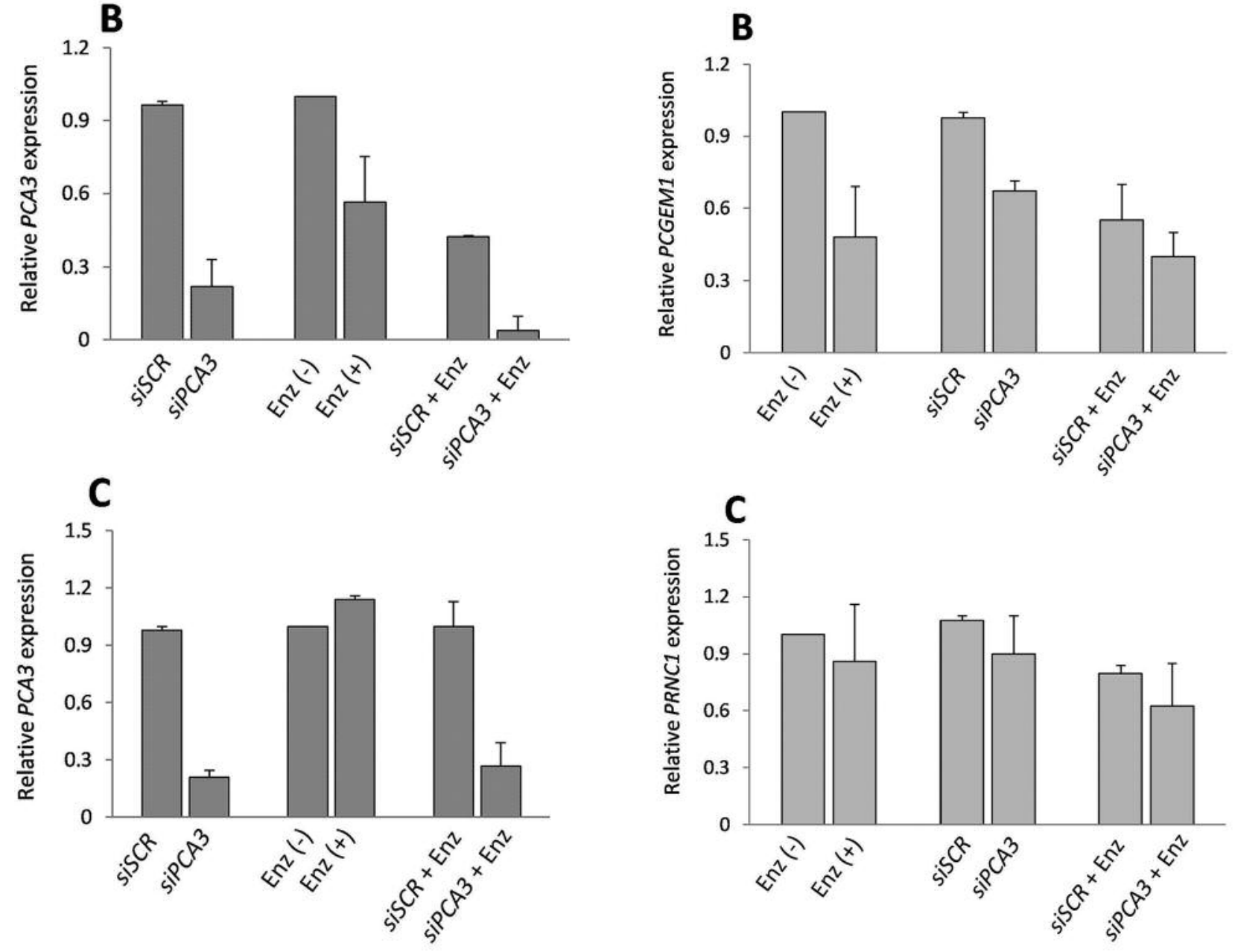

Figure 1. The effect of PCA3 silencing and/or AR inhibition on PCA3 expression. $L N C a P(A), L N C a P-A R^{+}(B)$ and $V C a P$ cells $(C)$ were transfected with siPCA3 or control scramble (SCR) siRNA (siSCR) and enzalutamide (Enz) was added 6 later at medium change. PCA3 expression was analyzed by $q P C R$. Results of three experiments were assessed. Basal levels were taken as ' 1 ' and changes were given in 'fold' changes. Shown are mean and maximum values.

Figure 2. The effect of PCA3 silencing and AR inhibition on AR-related genes. Cells were transfected with siPCA3 or siSCR and enzalutamide (Enz) was added 6 later at medium change. Cells were grown for $36 \mathrm{~h}$ and PCA3 expression was analyzed by qPCR. Results of three experiments were assessed. Basal levels were taken as ' 1 ' and changes were given in 'fold changes. Expression status of PSA (A), PCGEM1 $(B)$ and PRNC1 (C) is illustrated in LNCaP-AR+ cells. 
Table I. The effect of PCA3 silencing and/or Enz on the viability of PCA cells (\% of control cells).

\begin{tabular}{|c|c|c|c|c|c|c|c|c|c|c|c|c|c|c|}
\hline \multirow[t]{2}{*}{ Cell line } & \multicolumn{2}{|c|}{$\begin{array}{c}\text { Enz } \\
500 \mathrm{nM}\end{array}$} & \multicolumn{2}{|c|}{$\begin{array}{c}\text { Enz } \\
5 \mu \mathrm{M}\end{array}$} & \multicolumn{2}{|c|}{ siSCR } & \multicolumn{2}{|c|}{ siPCA3 } & \multicolumn{2}{|c|}{$\begin{array}{c}\text { siSCR + } \\
500 \mathrm{nM} \mathrm{Enz}\end{array}$} & \multicolumn{2}{|c|}{$\begin{array}{c}\text { siPCA3 + } \\
500 \mathrm{nM} \mathrm{Enz}\end{array}$} & \multicolumn{2}{|c|}{$\begin{array}{l}\text { siPCA3+ } \\
5 \mu \mathrm{M} \text { Enz }\end{array}$} \\
\hline & $36 \mathrm{~h}$ & $72 \mathrm{~h}$ & $36 \mathrm{~h}$ & $72 \mathrm{~h}$ & $36 \mathrm{~h}$ & $72 \mathrm{~h}$ & $36 \mathrm{~h}$ & $72 \mathrm{~h}$ & $36 \mathrm{~h}$ & $72 \mathrm{~h}$ & $36 \mathrm{~h}$ & $72 \mathrm{~h}$ & $36 \mathrm{~h}$ & $72 \mathrm{~h}$ \\
\hline $\mathrm{LNCaP}$ & 97 & 94 & 87 & 68 & 91 & 84 & 87 & 75 & 89 & 79 & 85 & 73 & 84 & 68 \\
\hline $\mathrm{LNCAP}_{-} \mathrm{AR}^{+}$ & 98 & 94 & 88 & 70 & 98 & 93 & 92 & 73 & 96 & 92 & 88 & 70 & 88 & 60 \\
\hline $\mathrm{VCaP}$ & 93 & 92 & 88 & 79 & 96 & 95 & 92 & 89 & 95 & 91 & 92 & 82 & 87 & 78 \\
\hline
\end{tabular}

Enz, Enzalutamide; siSCR, negative scramble (SCR) control siRNA; siPCA3, prostate cancer antigen 3 siRNA.

Table II. Surviving fractions (\% of control) of PCa cells following 10 days of incubation with siRNAs (PCA3 and siSCR) and Enz.

\begin{tabular}{|c|c|c|c|c|c|c|c|c|c|}
\hline Cell lines & $\begin{array}{l}\text { Control } \\
\text { cells }\end{array}$ & $\begin{array}{c}\mathrm{Enz} \\
500 \mathrm{nM}\end{array}$ & $\begin{array}{c}\text { Enz } \\
5 \mu \mathrm{M}\end{array}$ & $\operatorname{siSCR}$ & siPCA3 & $\begin{array}{c}\text { siSCR + } \\
500 \mathrm{nM} \mathrm{Enz}\end{array}$ & $\begin{array}{c}\mathrm{si} P C A 3+ \\
500 \mathrm{nM} \text { Enz }\end{array}$ & $\begin{array}{c}\operatorname{siSCR}+ \\
5 \mu \mathrm{M} \text { Enz }\end{array}$ & $\begin{array}{l}\text { siPCA3+ } \\
5 \mu \mathrm{M} \text { Enz }\end{array}$ \\
\hline LNCaP & 100 & 90 & 68 & 88 & 67 & 83 & 55 & 53 & 32 \\
\hline $\mathrm{LNCaP}^{-\mathrm{AR}^{+}}$ & 100 & 84 & 62 & 93 & 65 & 88 & 60 & 52 & 21 \\
\hline $\mathrm{VCaP}$ & 100 & 93 & 78 & 90 & 79 & 84 & 69 & 63 & 42 \\
\hline
\end{tabular}

Enz, Enzalutamide; siSCR, negative scramble (SCR) control siRNA; siPCA3, prostate cancer antigen 3 siRNA.

Table III. Relative levels of apoptotic nuclesomes in PCa cells after 36 h of irradiation and/or incubation with siPCA3 and Enz.

\begin{tabular}{|c|c|c|c|c|c|c|c|c|}
\hline Cell lines & $\begin{array}{c}\text { Control } \\
\text { cells }\end{array}$ & $\begin{array}{c}\text { Enz } \\
500 \mathrm{nM}\end{array}$ & $\begin{array}{c}\text { Radiation } \\
5 \mathrm{~Gy}\end{array}$ & Enz+Rad & $\operatorname{si} P C A 3$ & $\begin{array}{c}\text { siPCA3+ } \\
\text { Enz }\end{array}$ & $\begin{array}{c}\text { siPCA3 + } \\
\quad \operatorname{Rad}\end{array}$ & $\begin{array}{l}\text { siPCA3+ } \\
\text { Enz+Rad }\end{array}$ \\
\hline $\mathrm{LNCaP}$ & 1 & 2.8 & 1.6 & 3.6 & 2.1 & 4 & 2.7 & 5.6 \\
\hline $\mathrm{LNCAP}^{-\mathrm{AR}^{+}}$ & 1 & 2.1 & 1.9 & 3 & 2 & 2.9 & 2.5 & 3.4 \\
\hline $\mathrm{VCaP}$ & 1 & 2.1 & 1.6 & 2.2 & 1.9 & 2.6 & 2.0 & 2.9 \\
\hline
\end{tabular}

Enz, Enzalutamide; siPCA3, prostate cancer antigen 3 siRNA; Rad, irradiation.

We showed that siRNA-mediated PCA3 targeting leads to effective $P C A 3$ silencing. The extent of knockdown was similar to that reported by Ferreria et al. (11), confirming that targeting exon 4 leads to effective PCA3 silencing. On the other hand, we also identified that enzalutamidemediated AR blockade mimics $P C A 3$ targeting and downregulates $P C A 3$ to a substantial extent in $\mathrm{LNCaP}$ and $\mathrm{LNCaP}_{-} \mathrm{AR}^{+}$cells. If combined, $P C A 3$ knockdown and enzalutamide synergistically down-regulated $P C A 3$ further, with this effect being more pronounced in $\mathrm{LNCaP}-\mathrm{AR}^{+}$cells. Unexpectedly, enzalutamide had no effect on $P C A 3$ in $\mathrm{VCaP}$ cells. Yet, we do not know the basis of this differential observation in $\mathrm{VCaP}$ cells, that might be associated with the lower anti-proliferative effect of AR inhibition and/or PCA3 silencing in these cells (see below).
Before exploring the effect of PCA3 knockdown on cell viability, we first assessed its consequence on AR-related genes. Similar to enzalutamide-mediated AR blockade, PCA3 silencing suppressed PSA and PCGEMI expression and heightened enzalutamide-mediated down-regulation of these genes, proving that $P C A 3$ is involved in AR signaling. Intriguingly, we detected a weak effect of $P C A 3$ silencing or enzalutamide on $P R N C 1$ expression. Data on the involvement of PRNCl in PCa and AR signaling is inconsistent. An early report has described that $P R N C R 1$ and PCGEMI can enhance AR-mediated gene activation programs and implicated these lncRNAs as a required component of CRPC (17). In a subsequent study, Prensner et al. (18) performed a comprehensive RNA-sequencing analysis and provided evidence that $P C G E M I$ but not $P R N C R I$ was associated with 




\section{B}

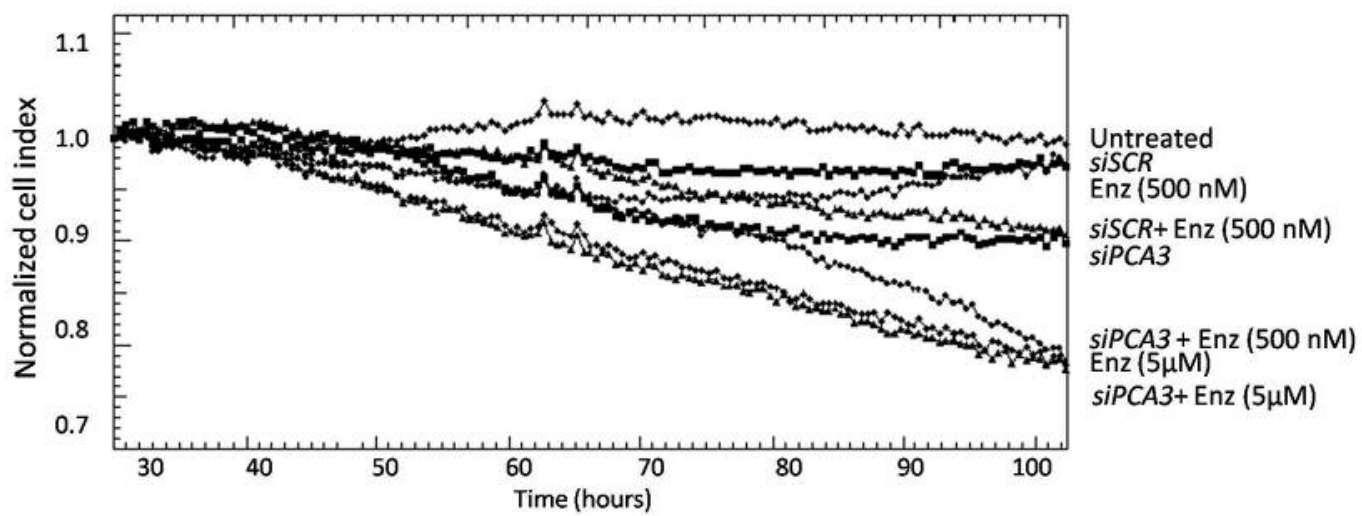

Figure 3. Real-time monitoring of the growth of PCA3-silenced and/or AR-blocked PCa cells. Following a 3-day growth in hormone-free conditions, cells were transfected with siPCA3 or siSCR and enzalutamide (Enz) was added 6 later at medium change. Cells were grown for further 72 h. At start of incubation value of cell index was taken as ' 1 ', changes during treatment were calculated. Examples of $L N C a P-A R^{+}(A)$ and VCaP cells (B) are shown.

PCa. However, they found that none of these molecules interacted with AR concluding that neither gene was a component of AR signaling. In a more recent article, Parolia et al. (19) described PCGEMI as an in vivo AR-regulated transcript with potential nuclear and/or cytoplasmic functions. Our findings are supportive of data that PCGEM1 but not PRNC1 is a component of AR signaling and may be involved in CRPC, because we showed that both enzalutamide treatment and $P C A 3$ silencing regulated PCGEMI down, whereas $P R N C l$ was hardly affected by AR targeting.

A few previous articles have reported that targeting $P C A 3$ results in the loss of cell growth, thus making $P C A 3$ a potential therapeutic target in $\mathrm{PCa}(11,13)$. Our findings confirm the outcomes of these reports and reveal that $P C A 3$ silencing reduces the viability of $\mathrm{PCa}$ cells. More importantly, we showed for the first time that $P C A 3$ silencing potentiates the effects of enzalutamide-mediated
AR inhibition by down-regulating AR-related genes and cutting the viability of PCa cells. The combined action was more effective in AR-overexpressing cells, which indicates that $P C A 3$ silencing modulates the AR signaling pathway. Consistent with this, Lemos et al. (13) showed that PCA3 silencing led to differential expression of several genes, including $\mathrm{AR}$ cofactors in LNCaP cells. Based on our findings, it appears that AR-overexpressing cells are more susceptible to $P C A 3$ silencing, which has clinical implications in tumors with high AR expression.

In VCaP cells, a representative of CRPC $(14,15)$, even if somewhat lower than in LNCaP and LNCAP-AR ${ }^{+}$cells, $P C A 3$ silencing led to a loss of cell growth and promoted the effect of AR inhibition. This might have implications in the treatment of PCa. As the clinical success of novel AR antagonists is not enduring in all patients (20) and acquired resistance to enzalutamide in the treatment of castration 
CRPC has been reported (21), targeting the PCA3 gene might be useful to potentiate AR antagonists and overcome acquired resistance to such agents.

In conclusion, our results reveal that targeting the $P C A 3$ gene, that is overexpressed in prostatic tumors, represents a therapuetic target in $\mathrm{PCa}$. PCA3 silencing reduces the viability of $\mathrm{PCa}$ cells and sensitizes them to enzaluatmidemediated AR inhibition via sub-maximal doses or radiotherapy in different PCa phenotypes, including CRPC. Further research, including the in vivo role of $P C A 3$ targeting, is needed to assess its clincal utilization in hormone-responsive and castration-resistant tumors.

\section{Acknowledgements}

This work is part of Ph.D. thesis of Emre Özgür and supported by Istanbul University Scientific Research Coordination Unit (Projeject numbers 46432 and 50702). The Authors would like to thank Astellas Inc. for providing enzalutamide. We also thank Mr. David F. Chapman for editing the manuscript lingusitically.

\section{References}

1 Siegel RL, Miller KD and Jemal A: Cancer statistics, 2015. CA Cancer J Clin 65: 5-29, 2015.

2 Yuan X, Li T, Wang H, Zhang T, Barua M, Borgesi RA, Bubley GJ, Lu ML and Balk SP: Androgen receptor remains critical for cell-cycle progression in androgen-independent CWR22 prostate cancer cells. Am J Pathol 169: 682-696, 2006.

3 Marques RB, Dits NF, Erkens-Schulze S, van Weerden WM and Jenster G: Bypassmechanisms of the androgen receptor pathway in therapy-resistant prostatecancer cell models. PLoS One 5: e13500, 2010

4 Pienta KJ and Bradley D: Mechanisms underlying the development of androgen-independent prostate cancer.Clin. Cancer Res 12: 1665-1671, 2006.

5 Guerrero J, Alfaro IE, Gómez F, Protter AA and Bernales S: Enzalutamide, an androgen receptor signaling inhibitor, induces tumor regression in a mouse model of castration-resistant prostate cancer. Prostate 73: 1291-1305, 2013.

6 Tran C, Ouk S, Clegg NJ, Chen Y, Watson PA, Arora V, Wongvipat J, Smith-Jones PM, Yoo D, Kwon A, Wasielewska T, Welsbie D, Chen CD, Higano CS, Beer TM, Hung DT, Scher HI, Jung ME and Sawyers CL: Development of a second-generation anti-androgen for treatment of advanced prostate cancer. Science 324: 787-790, 2009.

7 Clarke RA, Zhao Z, Guo AY, Roper K, Teng L, Fang ZM, Samaratunga H, Lavin MF and Gardiner RA: New genomic structure for prostate cancer specific gene PCA3 within BMCC1: Implications for prostate cancer detection and progression. PLoS One 4: E4995, 2009.

8 Bussemakers MJ, van Bokhoven A, Verhaegh GW, Smit FP, Karthaus HF, Schalken JA, Debruyne FM, Ru N and Isaacs WB: DD3: A new prostate-specific gene, highly overexpressed in prostate cancer. Cancer Res 59: 5975-5979, 1999.
9 Hessels D, Klein Gunnewiek JM, van Oort I, Karthaus HF, van Leenders GJ, van Balken B, Kiemeney LA, Witjes JA and Schalken JA: DD3(PCA3)-based molecular urine analysis for the diagnosis of prostate cancer. Eur Urol 44: 8-15, 2003.

10 Stephan C, Jung K and Ralla B: Current biomarkers for diagnosing of prostate cancer. Future Oncol 11: 2743-2755, 2015.

11 Ferreira LB, Palumbo A, de Mello KD, Sternberg C, Caetano MS, de Oliveira FL, Neves AF, Nasciutti LE, Goulart LR and Gimba ER: PCA3 noncoding RNA is involved in the control of prostate-cancer cell survival and modulates androgen receptor signaling. BMC Cancer 12: 507, 2012.

12 Tiryakioglu D, Bilgin E, Holdenrieder S, Dalay N and Gezer U: miR-141 and miR-375 induction and release are different from PSA mRNA and PCA3 upon androgen stimulation of LNCaP cells. Biomed Rep 1: 802-806, 2013.

13 Lemos AE, Ferreira LB, Batoreu NM, de Freitas PP, Bonamino $\mathrm{MH}$ and Gimba ER: PCA3 long noncoding RNA modulates the expression of key cancer-related genes in $\mathrm{LNCaP}$ prostate cancer cells. Tumour Biol 37(8): 11339-11348, 2016.

14 van Bokhoven A, Varella-Garcia M, Korch C, Johannes WU, Smith EE, Miller HL, Nordeen SK, Miller GJ and Lucia MS: Molecular characterization of human prostate carcinoma cell lines. The Prostate 57: 205-225, 2003.

15 Sobel RE and Sadar MD: Cell lines used in prostate cancer research: a compendium of old and new lines-Part 1. J Urol 173: 342-359, 2005

16 Özgür E, Mert U, Isin M, Okutan M, Dalay N and Gezer U: Differential expression of long non-coding RNAs during genotoxic stress-induced apoptosis in HeLa and MCF-7 cells. Clin Exp Med 13: 119-126, 2013.

17 Yang L, Lin C, Jin C, Yang JC, Tanasa B, Li W, Merkurjev D, Ohgi KA, Meng D, Zhang J, Evans CP and Rosenfeld MG: lncRNA-dependent mechanisms of androgen-receptor-regulated gene activation programs. Nature 500(7464): 598-602, 2013.

18 Prensner JR, Sahu A, Iyer MK, Malik R, Chandler B, Asangani IA, Poliakov A, Vergara IA, Alshalalfa M, Jenkins RB, Davicioni E, Feng FY and Chinnaiyan AM: The IncRNAs PCGEM1 and PRNCR1 are not implicated in castration resistant prostate cancer. Oncotarget 5: 1434-1438, 2014.

19 Parolia A, Crea F, Xue H, Wang Y, Mo F, Ramnarine VR, Liu HH, Lin D, Saidy NR, Clermont PL, Cheng H, Collins C, Wang $\mathrm{Y}$ and Helgason CD: The long non-coding RNA PCGEM1 is regulated by androgen receptor activity in vivo. Mol Cancer 14 : 46, 2015.

20 Bremmer F, Jarry H, Strauß A, Behnes CL, Trojan L and Thelen $\mathrm{P}$ : Increased expression of CYP17A1 indicates an effective targeting of the androgen receptor axis in castration resistant prostate cancer (CRPC). Springerplus 3: 574, 2014.

21 Penning TM: Mechanisms of drug resistance that target the androgen axis in castration resistant prostate cancer (CRPC). J Steroid Biochem Mol Biol 153: 105-113, 2015.

Received May 8, 2017

Revised May 16, 2017

Accepted May 17, 2017 